\title{
THE ATMOSPHERIC PRESSURE EFFECT ON MUON DATA NORMALIZATION BY SPECTRAL ANALYSIS STUDIES
}

\author{
Nivaor Rodolfo Rigozo and Adriano Petry
}

\begin{abstract}
This paper presents a study of the atmospheric pressure effects on ground cosmic ray muon time series, using the iterative regression spectral analysis method. Along the study, it was observed that the 34 periods present in the atmospheric pressure amplitude spectrum are present in the muon data amplitude spectra as well. It was concluded that the normalization of muon data is only efficient for periods shorter than nine days, in order to eliminate the atmospheric effects.
\end{abstract}

Keywords: cosmic rays, time series, spectral analysis.

RESUMO. Este artigo apresenta um estudo dos efeitos da pressão atmosférica nas series temporais de raios cósmicos, usando a metodologia da análise espectral pela iteração regressiva. Foi observado um total de 34 periodicidades presentes no espectro de amplitude da pressão atmostérica que também estão presentes no espectro de amplitude dos dados de muons. Conclui-se que a padronização dos dados de muons para eliminar os efeitos da pressão atmosférica é eficiente somente para períodos abaixo de 9 dias.

Palavras-chave: raios cósmicos, série temporal, análise espectral. 


\section{INTRODUCTION}

During the last years, the "space climate" research has been receiving special attention all over the world, due to the attempt of better understanding the physical phenomena generated in the Sun, their consequences in the interplanetary environment, and mainly on the Earth. Attention has been given to phenomena such as the solar wind interaction with the Earth's magnetic field, variations in the particle flow and energy that occur in the Sun and their consequences to the Earth's atmosphere and climate (Hoyt \& Schatten, 1997). Studies of the space climate, aim the collection of data to forecast the phenomena occurring in the Sun and the Earth's magnetosphere. Among the main solar phenomena, the Coronal Mass Ejections (CME) are the main causes of intense magnetic storms on Earth (Gosling et al., 1990, 1991).

CMEs are plasma eruptions from the Sun's outer atmosphere, in areas of closed magnetic field lines that are expelled into the interplanetary environment. Such areas, and the shocks they may generate, cause pronounced effects on the galactic cosmic rays' density, both locally, in the Earth's proximity or at considerably Iong distances within the heliosphere, exceeding 1 Astronomical Unit (149 $597870 \mathrm{~km}$ ). These effects on the energetic particles often may be used to identify CMEs in the interplanetary environment, where they are called "interplanetary ejections" (Cane, 2000; Munakata et al., 2005; Subramanian et al., 2008; Kane, 2010; Kane, 2011; Dragic et al., 2011). Thus, the cosmic rays (through their secondary components) become important evidences of the CME presence trending towards the Earth. Since the cosmic rays travel at the speed of light, they reach the Earth much earlier than the CMEs, and it is possible to forecast the occurrence of a geomagnetic storm (Kane, 2010; Kane, 2011).

One of the secondary components of the cosmic rays are the Muons. They are high energy particles originated from the interaction of high energy protons of the cosmic radiation in the Earth's atmosphere. Their formation and propagation in the atmosphere depend on the atmospheric pressure and temperature. According to Pomerantz \& Duggal (1971) the daily cosmic radiation variations are caused by the atmospheric variations. Thus, pressure and temperature effects cause the main interference in the study of the primary cosmic radiation's intensity of variations. They cause the air masses variations to produce variations in the detected cosmic rays flow (Simpson et al., 1953; Dorman \& Yanke, 1975). Owing to such effect a correction procedure of the atmospheric effects (pressure and temperature) on cosmic rays data has to be adopted (Kane, 2011; Kurguzova \& Charakhchian, 1979; Da Silva et al., 2007). Such correction, or normalization, removes the atmospheric effects (pressure and temperature) through the equation:

$$
\frac{\Delta I}{I}=\beta \Delta p+\int \alpha(h) \Delta T(h) d h
$$

where $\Delta p$ is the atmospheric pressure variation and $\Delta T$ is the temperature variation as a function of the $h$ altitude. The first term of the equation represents the barometric effect, where $\beta$ is the barometric coefficient. The second term of the equation represents the temperature effects, where $\alpha$ is the temperature coefficient which is dependent on the altitude (Bercovitch, 1967).

This article presents a study of the muon time series (20062010) through the iterative regression spectral analysis method in order to verify if the effect of the atmospheric pressure, represented by the first term to the right in Equation (1), is actually being removed in the muon data.

\section{METHODOLOGY}

All used data from the secondary component of the cosmic radiation (muons) were measured by the muon scintillator telescope installed in São Martinho da Serra - Brazil $\left(29.3^{\circ} \mathrm{S}, 53.5^{\circ} \mathrm{W}\right.$, with magnetic rigidity of approximately $14 \mathrm{GV}$ ), at the Observatório Espacial do Sul (Southern Space Observatory) - OES/CRSPE/INPE, financed by the NSF - National Science Foundation from the United States, through the Bartol Institute (Newark), by the University of Nagoya from Japan, and the by Brazilian government.

The muon time series and pressure used during this work was from December 1, 2006 throughout September 18, 2010. In this study only the daily averages of the gross data were used (Fig. 1), and the normalized data, for the atmospheric pressure expressed by Equation (1) (Fig. 2) in the Vertical, North, South, East, West, Northwest, Northeast, Southwest and Southeast directions. The $\beta$ values used for the barometric normalization (presented in Equation (1)) of the muon data are shown in Table 1.

The iterative regression spectral analysis method was adopted in this study in search of the periodicities present in the muon time series and pressure. The iterative regression method uses a simple sine function with three unknown parameters: $a_{o}=$ amplitude, $a_{1}=$ frequency and $a_{2}=$ phase (Wolberg, 1967; Rigozo et al., 2005). The method's initial step is the conditional function definition that is:

$$
F=Y+a_{0} \sin \left(a_{1} t+a_{2}\right)
$$

where $Y$ is the signal (time series), $t$ is the time and $a_{o}, a_{1}$ and $a_{2}$ are the three parameters to be determined. Two hundred was the maximum number of iterations used to determine the three parameters (Rigozo et al., 2005). This method determines each parameter's standard deviation and this is one of its advantages. 

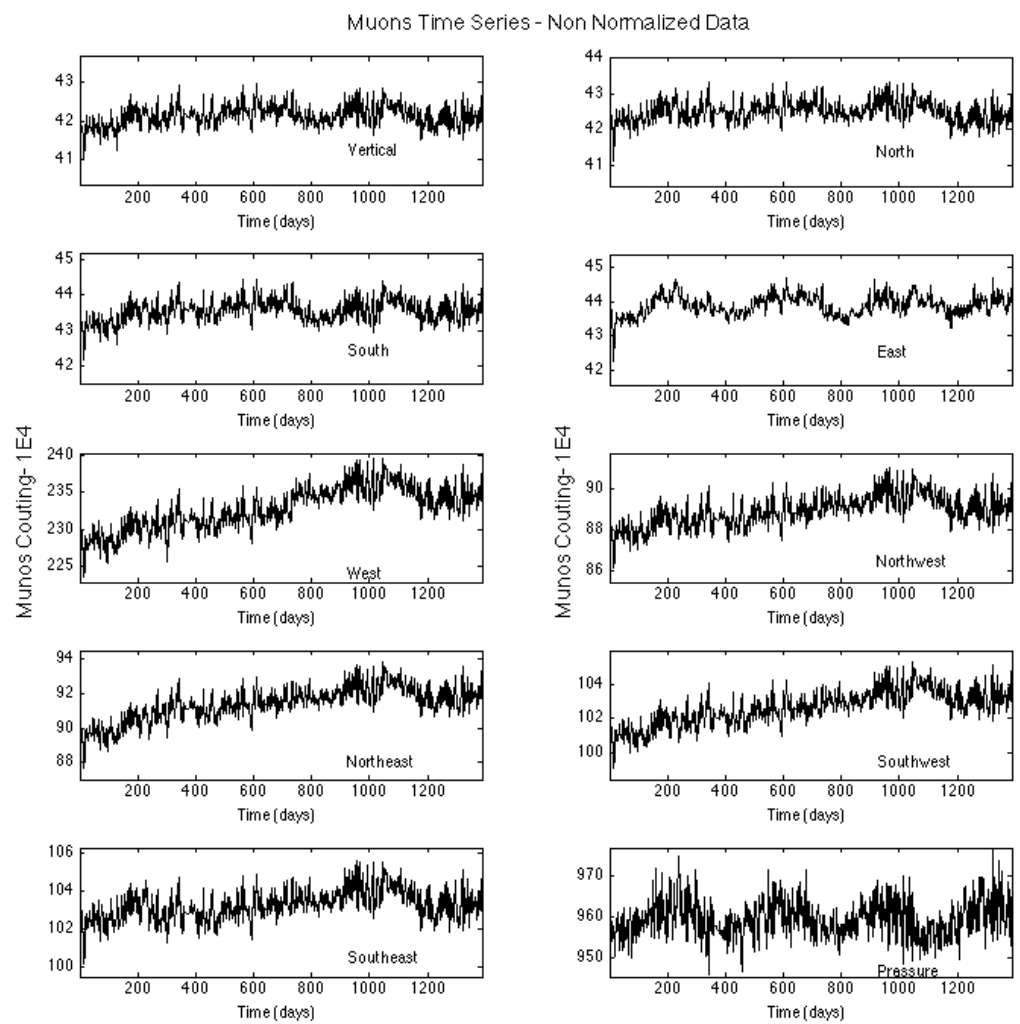

Figure 1 - Time series of the muon detector's daily average (non normalized data) for channels: Vertical, North South, East, West, Northwest, Northeast, Southwest, Southeast and Pressure from 2006 to 2010.
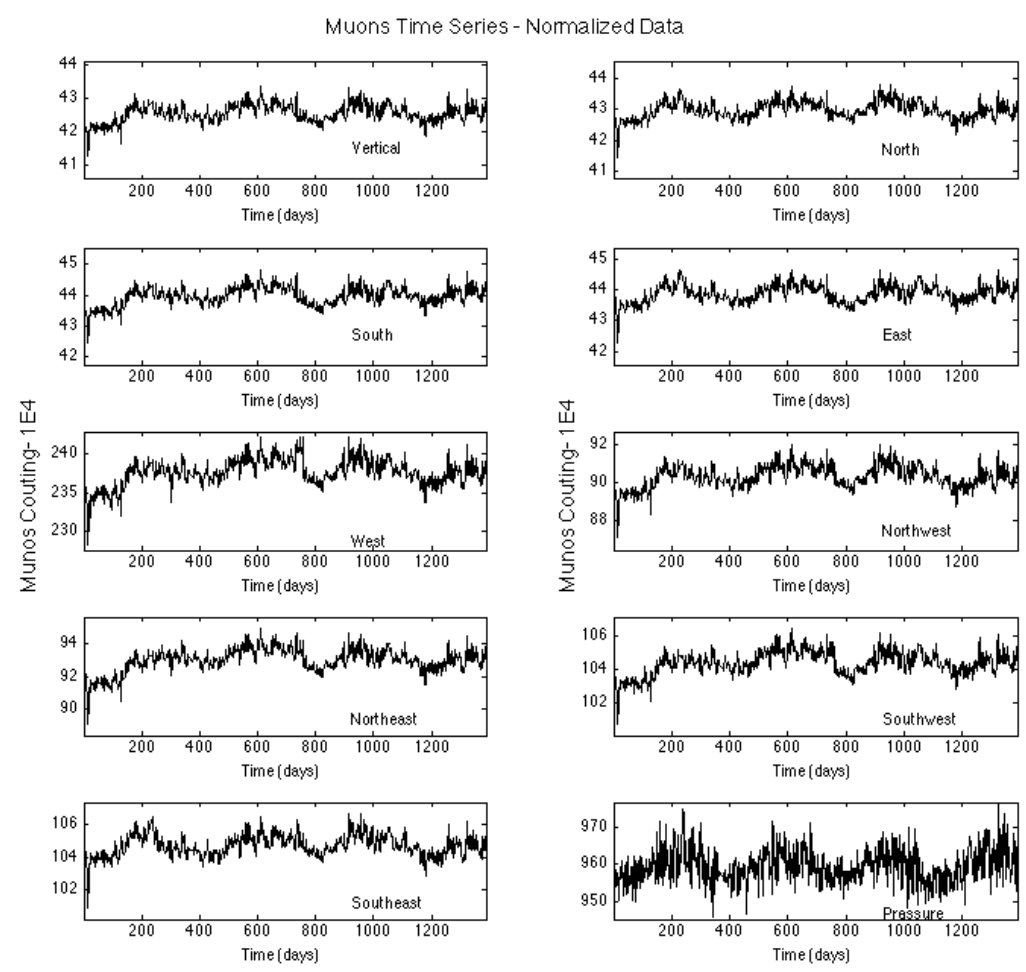

Figure 2 - Time series of the muon detector's normalized daily average for channels: Vertical, North, South, East, West, Northwest, Northeast, Southwest, Southeast and Pressure from 2006 to 2010. 
Table 1 - Correlation of the atmospheric pressure periodicities with the muon data (non normalized) for channels: Vertical, North, South, East, West, Northwest, Northeast, Southwest, Southeast.

\begin{tabular}{|c|c|c|c|c|c|c|c|c|c|}
\hline Periods & East & North & Northeast & Northwest & South & Southeast & Southwest & Vertical & West \\
\hline 374.00 & 0.68 & 0.85 & 0.83 & - & - & 0.69 & 0.99 & - & - \\
\hline 108.25 & -0.64 & -0.66 & -0.61 & -0.69 & - & -0.54 & - & -0.62 & - \\
\hline 34.84 & -0.63 & - & - & -0.77 & -0.61 & - & 0.54 & -0.51 & - \\
\hline 28.19 & -0.98 & -0.95 & -0.93 & -0.98 & -1 & - & - & -0.99 & -1 \\
\hline 24.39 & -0.9 & -0.93 & -0.96 & -0.78 & -0.89 & -0.95 & - & -0.99 & -0.72 \\
\hline 24.33 & -0.65 & -0.69 & -0.77 & -0.64 & -0.67 & -0.79 & - & -0.89 & -0.56 \\
\hline 23.75 & -1 & -1 & - & - & -1 & - & - & -1 & -0.99 \\
\hline 23.25 & -0.93 & -0.92 & -0.95 & -0.94 & -0.96 & -0.96 & -0.51 & -0.95 & -0.95 \\
\hline 23.19 & -0.88 & -0.94 & -0.92 & -0.92 & -0.93 & -0.93 & - & -0.96 & -0.95 \\
\hline 21.66 & - & -0.99 & -0.98 & -0.98 & -0.99 & -0.98 & - & -0.99 & -0.99 \\
\hline 20.54 & -0.75 & -0.66 & -0.6 & -0.82 & -0.87 & -0.91 & - & -0.98 & -0.96 \\
\hline 18.98 & -0.99 & -0.99 & -1 & -0.99 & -0.99 & -0.99 & - & -1 & -0.93 \\
\hline 16.79 & -0.87 & -0.83 & -0.86 & -0.74 & -0.9 & -0.86 & - & -0.9 & -0.62 \\
\hline 15.86 & -0.98 & -0.98 & -0.98 & -0.97 & -0.97 & -0.95 & - & -0.9 & -0.97 \\
\hline 14.17 & -0.76 & - & - & - & -0.77 & - & - & - & -0.61 \\
\hline 13.96 & -0.91 & -0.92 & -0.96 & -0.91 & -0.89 & -0.94 & - & -0.89 & -0.88 \\
\hline 13.11 & -0.98 & -0.97 & -0.94 & -0.76 & -0.99 & -0.95 & - & -0.99 & -0.78 \\
\hline 12.52 & -0.73 & -0.73 & -0.63 & -0.74 & -0.73 & -0.62 & - & -0.76 & -0.83 \\
\hline 12.23 & -0.85 & -0.92 & -0.85 & -0.98 & -0.88 & -0.84 & - & -0.79 & -0.98 \\
\hline 11.69 & -0.97 & -0.97 & -0.97 & -0.95 & -0.96 & -0.95 & - & -0.97 & -0.96 \\
\hline 11.16 & -1 & -1 & -0.99 & -0.99 & -0.99 & -1 & - & -0.95 & -0.97 \\
\hline 10.76 & -0.99 & -0.97 & -0.94 & -0.86 & -0.95 & -0.99 & - & -0.94 & -0.98 \\
\hline 10.59 & -0.95 & -0.94 & -0.9 & -0.95 & -0.98 & -0.98 & - & -0.98 & -0.98 \\
\hline 10.13 & -0.83 & -0.82 & -0.82 & - & -0.82 & -0.8 & - & -0.83 & - \\
\hline 9.51 & -0.68 & -0.73 & -0.71 & -0.78 & -0.61 & -0.64 & - & -0.62 & - \\
\hline 9.39 & -0.77 & -0.78 & -0.8 & -0.81 & -0.79 & -0.84 & - & -0.97 & -0.78 \\
\hline 8.63 & -0.96 & -0.96 & -0.92 & -0.9 & -0.85 & -0.96 & - & -0.85 & -0.96 \\
\hline 8.56 & -0.8 & -0.8 & -0.83 & -0.87 & -0.73 & -0.77 & - & -0.73 & -0.82 \\
\hline 7.7 & -0.87 & -0.86 & -0.9 & -0.92 & -0.88 & -0.9 & -0.65 & -0.87 & -0.88 \\
\hline 7.27 & -0.9 & -0.87 & -0.91 & -0.98 & -0.92 & -0.94 & - & -0.9 & -0.96 \\
\hline 7.03 & -0.89 & -0.84 & -0.97 & -0.95 & -0.97 & -0.93 & - & -0.97 & -0.97 \\
\hline 6.11 & -0.93 & -0.92 & -0.9 & -0.57 & -0.55 & -0.51 & - & -0.93 & -0.59 \\
\hline 5.94 & -0.94 & -0.94 & -0.9 & -0.91 & -0.95 & -0.92 & - & -0.95 & -0.96 \\
\hline 5.76 & -0.74 & -0.9 & -0.97 & -0.56 & -0.99 & - & - & -0.96 & -0.53 \\
\hline
\end{tabular}

This allows selection of the most important amplitudes (above $95 \%$ of reliability), representing values greater than the amplitude/standard deviation ratio.

\section{RESULTS}

Through the correlation among the channels, it is possible to verify if the muon measurement channels are giving the same answers to possible variations caused by physical phenomena. Thus, the muon time series present a high correlation among the Vertical, North, South, East, West, Northwest, Northeast, Southwest and Southeast channels, with a correlation coefficient vary- ing from 0.88 to 0.98 for the raw data and the normalized data. It is expected that each channel's spectral analyses practically present the same results.

Figure 3 shows the amplitude spectrum of the atmospheric pressure and the muon time series for the Vertical, North, South, East, West, Northwest, Northeast, Southwest and Southeast channels with $95 \%$ of reliability. As expected, the spectra of each channel did not present significant differences.

Figure 4 shows the amplitude spectrum for the time series, and also for the atmospheric pressure and the muon normalized data for the Vertical, North, South, East, West, Northwest, North- 
Muons Time Series - Raw Data
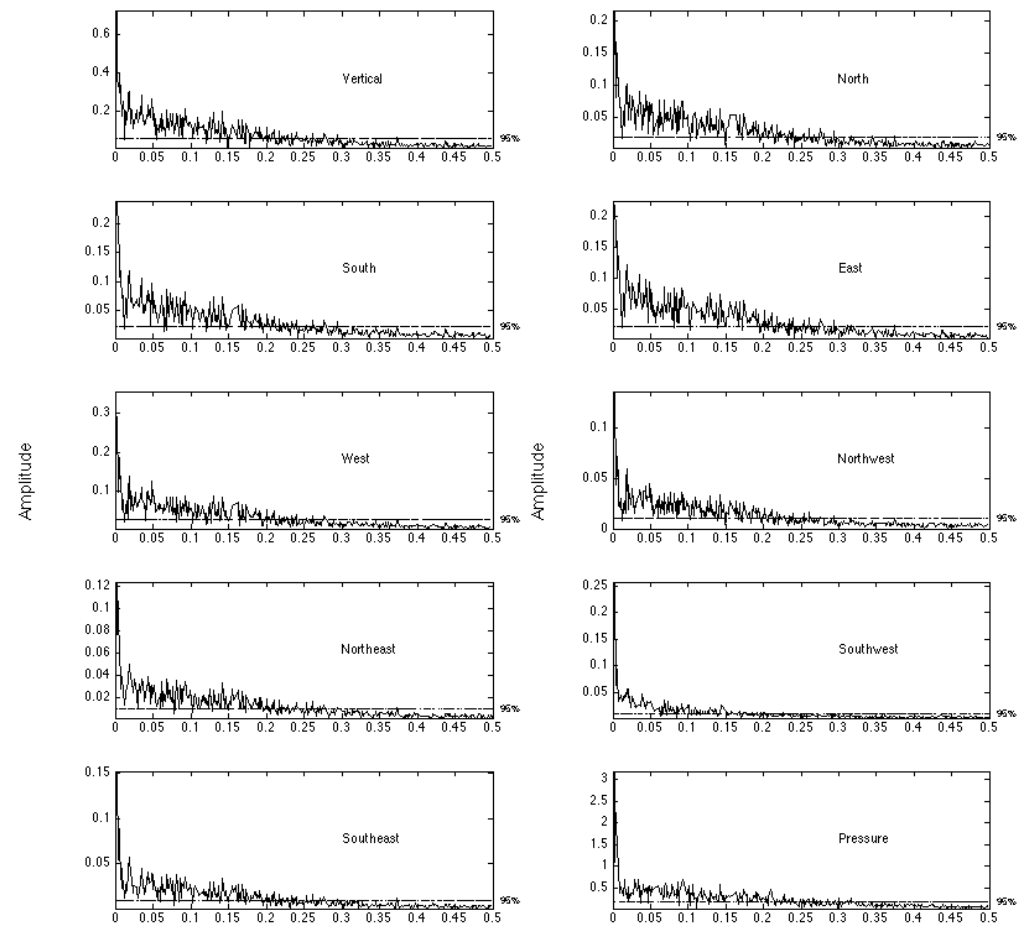

Frequency $\left(\right.$ days $^{-1}$ )

Frequency $\left(\right.$ days $^{-1}$ )

Figure 3 - Amplitude spectrum of the muon (non normalized) and pressure data.
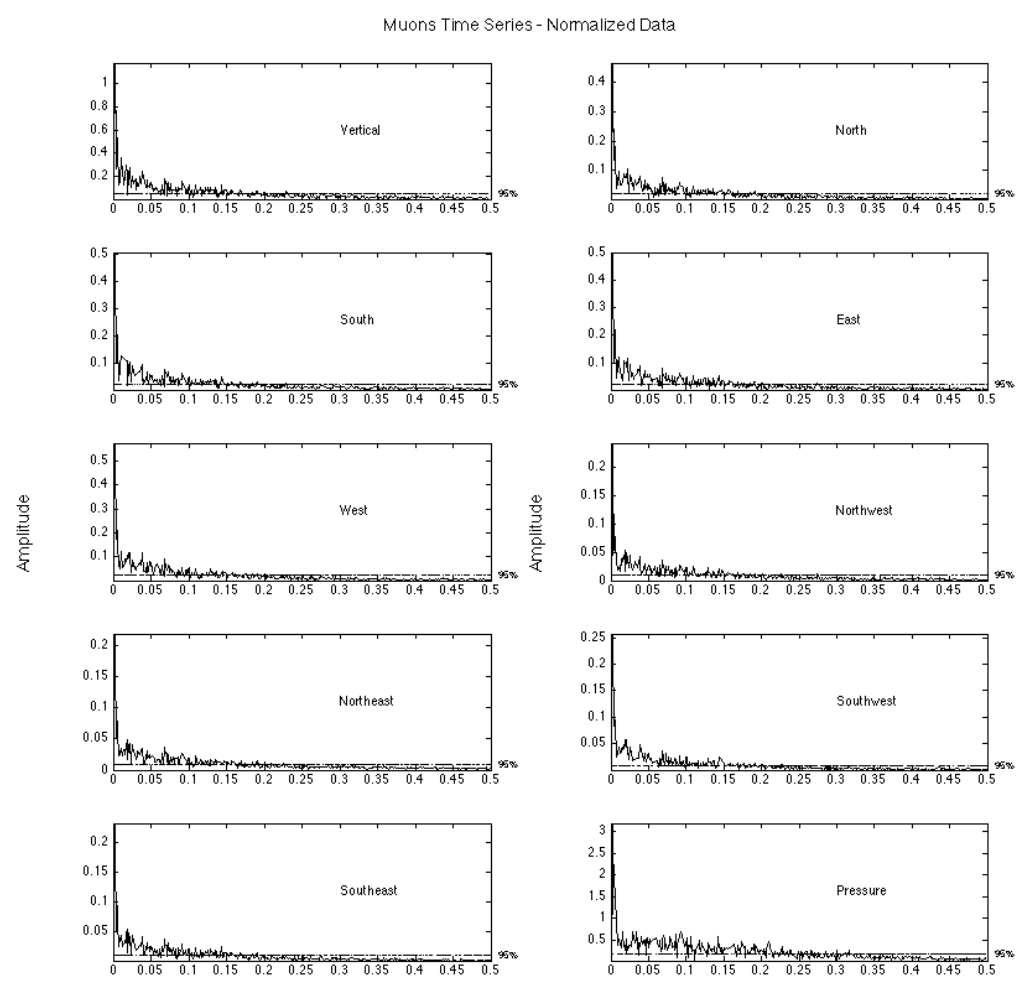

Frequency $\left(\right.$ days $^{-1}$ )

Frequency $\left(\right.$ days $^{-1}$ )

Figure 4 - Amplitude spectrum of the normalized muon and pressure data. 
east, Southwest and Southeast channels, with 95\% of reliability. In this case, significant differences in the spectra of each channel were not observed also.

The 34 periodicities listed in Table 2 represent the signals found in the atmospheric pressure time series, with reliability level above 95\%, and they are also present in the (non normalized) muon data for all channels. Table 2, also shows the correlation coefficients $(r)$ for reconstruction of the periodic signals found in the atmospheric pressure and the muon data (for all channels) time series. It may be observed that the two time series present a negative correlation; in other words, when the atmospheric pressure increases, detection of the muons decreases, for all channels. This fact did not happen only during the 374 day-period, when a positive correlation was observed for the channels. In order to explain this positive correlation between the atmospheric pressure and the muon data, one hypothesis could be that this annual variation of pressure is due to orbital parameters (the Earth's translation movement), not to the atmospheric parameters.

Table 2 - The $\beta$ values used in the barometric normalization in the muon data.

\begin{tabular}{|c|c|}
\hline$\beta$ & Direction \\
\hline-0.12 & $\mathrm{~V}$ \\
-0.12 & $\mathrm{~N}$ \\
-0.12 & $\mathrm{~S}$ \\
-0.11 & $\mathrm{E}$ \\
-0.12 & $\mathrm{~W}$ \\
-0.11 & $\mathrm{NE}$ \\
-0.12 & $\mathrm{NW}$ \\
-0.11 & $\mathrm{SE}$ \\
-0.12 & $\mathrm{SW}$ \\
\hline
\end{tabular}

The periodicities of 4.97, 5.25 and 6.46 days (Fig. 3), represent the periodicities found in the muon data, with reliability above $95 \%$, but that was not observed in the atmospheric pressure time series with a significant reliable level (of 95\%).

Table 3 shows the correlation coefficients $(r)$ for reconstruction of the periodic signals found in the atmospheric pressure and the normalized muon data (for all channels) time series. In this Table it may be observed that nine periodicities, highlighted by the darker strip, that were present in Table 2, and that were due to the pressure influence, may still be detected even after the normalization by Equation (1). Twelve periodicities (highlighted in a lighter strip) may be observed with a positive correlation coefficient with the atmospheric pressure, in other words, increasing the pressure, there is an increase of muon detection, and this goes against the phenomenon's physics that determines exactly the opposite. This suggests that the normalization is inserting frequency signals in the muon time series that do not really exist.

Comparing the periodicities found in the non normalizedmuon data (Fig. 3) with the periodicities found in the normalized muon data (Fig. 4), some different aspects were observed among them:

1) It is clear that normalization through Equation (1) carries out a filtering of the muon data, eliminating, "smoothing", and inserting some periodicities in the muon time series;

2) Elimination of the atmospheric pressure effects by normalization of the muon data through Equation (1) is more efficient only for periods shorter than nine days. However, for periods longer than that, the atmospheric pressure effects are not eliminated and, in addition, there is data contamination with signals that were not present prior to normalization;

3) The periodicities of 4.97, 5.25 and 6.46 days, which do not correspond to atmospheric variations, were eliminated from the muon data for all channels. This implies that normalization may be eliminating possible physical phenomena that are not atmospheric effects (such as the possible occurrences of coronal mass ejections that reached the Earth).

The cosmic radiation intensity is not constant, it continually varies for different time scales. Its flow incident on the Earth's atmosphere is basically modulated by three processes: 1) Variations of the solar wind within the heliosphere (with time scale 10 to 1,000 years); 2) Variations of the Earth's magnetic field (10010,000 years); 3) Variations of the interstellar flow outside the heliosphere ( $>106$ years) (Kirkby et al., 2004).

Variations with short periods of time and with a terrestrial origin are called seasonal and diurnal variations, caused by differences in the Earth's atmospheric structure between the winter and summer seasons, and between the day and night (Dorman, 2004; Da Silva et al., 2004; Vieira et al., 2012). Other variation of the cosmic radiation, with a climatic origin, but with glacial periods, is due to orbital parameters. Though this mechanism is still not yet proven, it demonstrates the cosmic radiation variations with 100,000 year-cyclicity. Other mechanisms may be associated to the geodynamo's orbital modulation, therefore, modulating the intensity and direction of the geomagnetic field, and/or the correlations of orbital parameters with the solar wind in the heliosphere (Kirkby et al., 2004). 
Table 3 - Correlation of the atmospheric pressure periodicities with the (normalized) muon data for channels: Vertical, North, South, East, West, Northwest, Northeast, Southwest, Southeast.

\begin{tabular}{|c|c|c|c|c|c|c|c|c|c|}
\hline Periods & East & North & Northeast & Northwest & South & Southeast & Southwest & Vertical & West \\
\hline 1106.27 & 0.97 & 0.97 & 0.96 & 0.9 & 0.96 & 0.99 & 0.7 & 0.99 & - \\
374.00 & 0.98 & 0.99 & 0.99 & 0.97 & 0.96 & 0.98 & 0.99 & 0.98 & 0.95 \\
361.76 & 1 & 0.98 & 0.99 & 0.97 & 0.96 & 1 & - & - & - \\
108.25 & - & -0.61 & -0.71 & - & - & - & - & - & - \\
97.53 & 0.94 & 0.93 & 0.93 & 0.54 & 0.96 & 0.92 & 0.61 & 0.95 & 0.71 \\
79.51 & - & 0.52 & 0.61 & 0.96 & - & 0.89 & 0.94 & - & 0.95 \\
69.21 & 0.56 & - & 0.76 & 0.75 & - & 0.76 & 0.78 & -0.55 & 0.6 \\
44.29 & 0.62 & 0.65 & 0.62 & 0.6 & 0.63 & 0.65 & 0.66 & 0.64 & 0.57 \\
28.95 & -0.74 & -0.65 & -0.62 & -0.64 & -0.77 & -0.82 & -0.77 & -0.75 & -0.8 \\
26.09 & 0.99 & 0.73 & 0.97 & 0.67 & 0.89 & 0.99 & 0.82 & 0.59 & - \\
23.25 & -0.55 & - & - & -0.57 & -0.5 & - & -0.53 & -0.7 & - \\
23.19 & - & - & - & - & - & - & - & -0.68 & - \\
20.92 & 0.87 & 0.56 & 0.55 & - & 0.78 & 0.77 & - & 0.67 & 0.65 \\
20.54 & - & -0.82 & - & -0.51 & - & - & -0.8 & -0.82 & - \\
15.49 & 0.76 & - & 0.76 & - & 0.79 & 0.76 & - & 0.86 & - \\
15.45 & 0.83 & 0.97 & 0.92 & 0.54 & 0.86 & 0.93 & - & 0.92 & - \\
14.55 & - & - & - & - & - & - & - & -0.54 & - \\
14.17 & - & - & - & 0.51 & 0.55 & 0.53 & 0.56 & - & 0.99 \\
13.12 & -0.85 & -0.82 & -0.53 & - & -0.86 & -0.75 & - & -0.99 & - \\
13.11 & -0.87 & -0.77 & -0.53 & - & -0.93 & -0.77 & - & -0.97 & - \\
12.92 & 0.6 & 0.7 & 0.62 & - & 0.96 & 0.66 & 0.57 & - & 1 \\
12.23 & -0.75 & -0.69 & -0.53 & -0.86 & -0.79 & -0.8 & -0.93 & -0.61 & -0.87 \\
11.7 & -0.74 & -0.63 & -0.64 & - & -0.77 & -0.76 & -0.59 & -1 & - \\
11.28 & 0.59 & 0.66 & 0.63 & - & 0.65 & - & - & - & - \\
10.04 & - & 0.51 & 0.51 & 0.62 & 0.51 & - & 0.6 & 0.51 & - \\
9.94 & 0.5 & 0.69 & 0.73 & 0.64 & 0.54 & 0.59 & 0.58 & - & 0.91 \\
\hline
\end{tabular}

Our proposal to efficiently eliminate the atmospheric pressure effects on the muon data is: 1 - To identify all periodicities that are due to atmospheric pressure influence (Table 2); 2 - To rebuild such dependence (periodicities) in the muon data; 3 - To subtract such reconstruction in the muon time series. With this we will have a more refined muon time series in relation to the atmospheric pressure effects.

\section{CONCLUSION}

This article presents a study of the atmospheric pressure effects on the muon detector time series through the classic spectral analysis using the iterative regression method.

During the study, a total of 34 periodicities belonging to the atmospheric pressure, present in the muon data, were observed. Nine of such periodicities are both in the non normalized data series and in the normalized series. Only the 374 day-period presents a positive correlation between the two time series, while the periodicities shorter than 374 days present a negative correlation in the non normalized time series.

It was also verified that the applied normalization equation efficiently eliminates the atmospheric pressure effects only for periods shorter than 9 days. Such normalization may be eliminating other signals, that are not due to the atmospheric pressure effects, such as the observed periods of 4.97, 5.25 and 6.46 days. Additionally, the normalization equation is also introducing frequency signals, to the muon time series, which have a positive dependence (correlation) with the atmospheric pressure.

To conclude, a procedure was presented (but it was not tested yet) to achieve a more efficient elimination of the atmospheric pressure effects on the muon data.

\section{ACKNOWLEDGMENTS}

The authors acknowledge the financial support given to this research work: N.R. Rigozo - CNPq (APQ 470605/2012-0 and, 303368/2012-8). 


\section{REFERENCES}

BERCOVITCH M. 1967. Atmospheric Effects on Cosmic Ray Monitors. In: Proceedings of the $10^{\text {th }}$ International Cosmic Ray Conference, Calgary, Canada, June 19-30, 269 pp.

CANE HV. 2000. Coronalmass ejections and forbush decreases. Space Science Reviews, 93: 55-77.

DA SILVA MR, CONTREIRA DB, MONTEIRO S et al. 2004. Cosmic ray muon observation at Southern Space Observatory - SSO $\left(29^{\circ} \mathrm{S}, 53^{\circ} \mathrm{W}\right)$. Astrophys. Space Sci., 290: 389-397.

DA SILVA MR, GONZALEZ WD, ECHER E, DAL LAGO A, VIEIRA LEA, GUARNIERI FL, LUCAS A, SCHUCH NJ \& MUNAKATA K. 2007. Multitaper spectral analysis of cosmic rays Sao Martinho da Serra's muon telescope and Newark's neutron monitor data. Revista Brasileira de Geofísica, 25 (Suppl. 2): 163-167.

DORMAN L. 2004. Cosmic Rays in the Earth's Atmosphere and Underground. Kluwer Academic Publisher, Dordrecht., 862 pp.

DORMAN LII \& YANKE VG. 1975. Development of the Theory of Meteorological Effects in Cosmic Rays. In: Proceedings from the $14^{\text {th }}$ International Cosmic Ray conference, München, Germany, August, 15-29. Volume 4 (MG Session and Pioneer Symposium), 1385 pp.

DRAGIĆ A, ANIĆ IN I, BANJANAC R, UDOVICIĆ V, JOKOVIĆ D, MALETIĆ D \& PUZOVIĆ J. 2011. Forbush decreases - clouds relation in the neutron monitor era. Astrophys. Space Sci. Trans., 7: 315-318.

GOSLING JT, BAME SJ, MCCOMAS DJ \& PHILLIPS JL. 1990. Coronal mass ejections and large geomagnetic storms. Geophys. Res. Lett., 17: 901-904.

GOSLING JT, McCOMAS DJ, PHILLIPS JL \& BAME SJ. 1991. Geomagnetic activity associated with Earth passage of interplanetary shock disturbances and coronal mass ejections. J. Geophys. Res., 96: 78317838.

HOYT DV \& SCHATTEN KH. 1997. The Role of the Sun in climate change, Oxford University Press. 288 pp.

KANE RP. 2010. Severe geomagnetic storms and Forbush decreases: interplanetary relationships reexamined. Ann. Geophys., 28: 479-489.
KANE RP. 2011. Directional muon telescope not useful for estimating the magnitudes of Forbush decreases and geomagnetic storms. Indian Journal of rado \& space Physics, 40: 76-84.

KIRKBY J, MANGINI A \& MULLER RA. 2004. The glacial cycles and cosmic rays. European Organization for Nuclear Research, CERN-PHEP/2004-027, 18 June. 1-16 p.

KURGUZOVA AI \& CHARAKHCHIAN TN. 1979. Temperature effect of the muon component of cosmic rays in the atmosphere. Geomagnetism and Aeronomy, 18: 403-407.

MUNAKATA K, KUWABARA T, BIEBER JW., EVENSON P, PYLE R, YASUE S, KATO C, FUJII Z, DULDIG ML, HUMBLE JE, SILVA MR, TRIVEDI NB, GONZALEZ WD \& SCHUCH NJ. 2005. CME-geometry and cosmic-ray anisotropy observed by a prototype muon detector network. Advances in Space Research, 36: 2357-2362.

POMERANTZ MA \& DUGGAL SP. 1971. The cosmic ray solar diurnal anisotropy. Space Science Reviews, 12: 75-130.

RIGOZO NR, ECHER E, NORDEMANN DJR, VIEIRA LEA \& FARIA HH. 2005, Comparative study between four classical spectral analysis methods. Applied Mathematics and Computation, 168: 411-430.

SIMPSON JA, FONGER W \& TREIMANT SB. 1953. Cosmic radiation intensity-time variations and their origin. I. Neutron intensity variation method and meteorological factors. Physical Review, 90(5): 934-950.

SUBRAMANIAN P, ANTIA HM, DUGAD SR, GOSWAMI UD, GUPTA SK, HAYASHI Y, ITO N, KAWAKAMI S, KOJIMA H, MOHANTY PK, NAYAK PK, NONAKA T, OSHIMA A, SIVAPRASAD K, TANAKA H \& TONWAR SC. 2008. Forbush decreases and turbulence levels at CME fronts. ESO, Astronomy \& Astrophysics, 1107-1118.

VIEIRA LR, DAL LAGO A, RIGOZO NR, DA SILVA MR, BRAGA CR, PETRY A \& SCHUCH NJ. 2012. Near 13.5-day periodicity in Muon Detector data during late 2001 and early 2002. Advances in Space Research, 49: $1615-1622$

WOLBERG JR. 1967. Prediction Analysis. D. Van Nostrand, 291 pp.

Recebido em 10 fevereiro, 2012 / Aceito em 26 abril, 2013

Received on February 10, 2012 / Accepted on April 26, 2013

\section{NOTES ABOUT THE AUTHORS}

Nivaor Rodolfo Rigozo. Ph.D. and M.Sc. in Space Geophysics (Instituto Nacional de Pesquisas Espaciais - INPE). B.Sc. in Physics (Pontifícia Universidade Católica do Rio Grande do Sul - PUC-RS). Currently works as associate researcher at the Divisão de Geofísica Espacial (DGE), a division of the Instituto Nacional de Pesquisas Espaciais (INPE)

Adriano Petry. Ph.D. in Computational Sciences, B.Sc. in Electrical Engineering (Universidade Federal do Rio Grande do Sul - UFRGS). Currently works as a technologist at Centro Regional Sul de Pesquisas Espaciais (CRS) of the Instituto Nacional de Pesquisas Espaciais (INPE) 